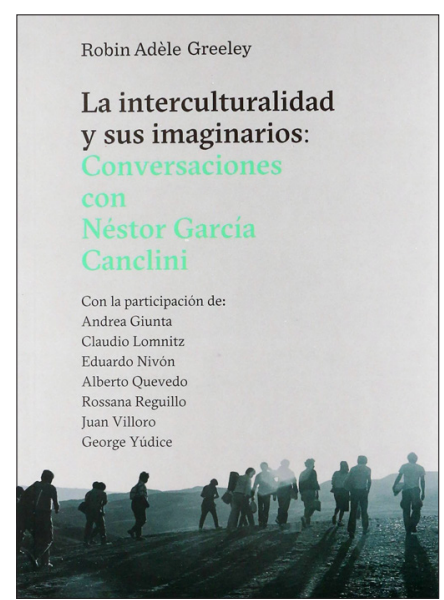

The New Happy World of Globalization

WITOLD JACORZYNSK

Centro de Investigaciones y Estudios Superiores en Antropología Social, Unidad Sureste, San Cristóbal de las Casas,

Chiapas, México lekvinik64@gmail.com

Desacatos 63, mayo-agosto 2020, pp. 171-177
- La interculturalidad y sus imaginarios: conversaciones con Néstor García Canclini Robin AdĖle GREELEY, 2018

Gedisa, México

\section{El nuevo mundo feliz de la globalización}

\author{
WITOLD JACORZYNSKI
}

amos la bienvenida a un libro sumamente original y descomunal, en forma de diálogos con uno de los más importantes intelectuales argentinos exiliado en México, Néstor García Canclini. Él dialoga con otros intelectuales de primera, en su mayoría latinoamericanos: Andrea Giunta, Claudio Lomnitz, Eduardo Nivón, Alberto Quevedo, Rossana Reguillo, Juan Villoro, George Yúdice, y finalmente, Robin Adèle Greeley, siendo esta última quien escribió una útil introducción, un repaso de los temas más importantes que marcan la rica trayectoria intelectual de García Canclini: hibridación, globalización e interculturalidad, ciudades, comunicación, ciudadanía y consumo, precarización de la vida cotidiana, juventud en una cultura posindustrial, migración, estética y arte. La originalidad del libro no se agota en la forma dialógica de la exposición, pues está incrustado de textos inéditos, documentos, fotos, textos leídos en varias conferencias y homenajes, un resumen curricular. Quien esté interesado en la biografía del autor argentino - y tenga muy buena vista - puede leer estos textos intercalados. Para los que no tienen buena vista, leer la letra excesivamente diminuta se vuelve una tortura. Esta riqueza que se ve y la que no se ve forman un todo impresionante, biográficamente rico, 
polifónico y hasta heteroglósico. Casi todo tipo de lector puede encontrar algo interesante en el libro. Acabamos de mencionar a los biógrafos, pero están también los aficionados a seguir la continuidad del pensamiento de García Canclini, los historiadores de las ideas, los recolectores de las confesiones de un migrante y exiliado. Como bien dice Robin Greeley en la introducción, este libro "tiene dos objetivos entrelazados: primero rastrear la historia y el desarrollo del esfuerzo intelectual multinivel de García Canclini, y segundo, abrirlo hacia nuevas ideas y fronteras" (p.51). Veamos esto punto por punto.

\section{El hombre y su obra}

Los diálogos con García Canclini, sus reminiscencias de la vida en Argentina y Francia en los años sesenta y setenta, su estancia doctoral en Francia con Paul Ricoeur, su exilio en México a partir de 1976, marcan las grandes pautas de su vida, no sólo académica sino espiritual, intelectual y moral. Al leer los primeros diálogos titulados "Migraciones de un investigador", el lector que conoce un poco sus libros tiene la impresión de que la vida y la obra del autor argentino corren en forma paralela. García Canclini se sitúa entre aquellos cuya vida no sólo define, sino además impone ciertas reflexiones y ahíncos que repercuten en su obra académica: suya es la vida del exiliado, del migrante, de un hombre híbrido, un filósofo, y posteriormente, de un antropólogo, un argentino, un mexicano, un latinoamericano. Suyas son las experiencias de los eternos ritos de paso que se vuelven normalidad mientras la normalidad se torna espuria y pasajera: a esto él le llama el "sentido migratorio intercultural" (p. 36).

Este sentido corresponde a su interés en las culturas populares, expresadas en los primeros libros de los ochenta, a saber: Las culturas populares en el capitalismo, de 1982, y Culturas híbridas. Estrategias para entrar y salir de la modernidad, de 1989 (2001):
Había que estudiar la lógica de estos movimientos, que no era sólo interna, estaba en interacción con otras condiciones nacionales e internacionales del capitalismo. Así comencé a darme cuenta de la interculturalidad, de la importancia de que esas culturas no fueron aisladas, como a veces se las pretende estudiar (p. 77).

El autor de estas palabras tampoco estaba aislado de la corriente turbulenta de aquellos tiempos. Una década antes, cuando regresó del viaje a Francia, al haber acabado su disertación doctoral sobre Maurice Marleau-Ponty, bajo la tutoría de Paul Ricoeur, enfrentó el rostro brutal de la dictadura en Argentina: "a medida que veía que se iban cerrando las puertas y que mataban a compañeros míos de la universidad, profesores, amigos, alumnos, empecé a escribir cartas para ver a dónde podíamos ir con María Eugenia Modena, antropóloga, mi esposa en ese momento" (p. 70). En 1976, se animaron a viajar y explorar. Cuando, al llegar a México, se enteraron de que a un amigo cercano lo habían secuestrado y asesinado en Argentina, se tomó la decisión: "fueron a mi casa, preguntaron por mí, mi mujer me dijo: 'No me importa si conseguiste trabajo en México. Vamos, nos quedamos allá"” (p. 70). A partir de entonces, México — su nuevo país de destinose volvió el destino de él, su esposa y su pequeña hija, pues no pudo pisar el suelo de su patria sino hasta 1983, cuando la dictadura acabó. A lo largo de Conversaciones..., García Canclini expresa la gratitud al país que lo acogió: "México fue muy receptivo con los que veníamos de países latinoamericanos. Eso lo convirtió, además, en una capital del pensamiento latinoamericano de primer nivel" (p. 71). Pero en otro diálogo agrega, de manera crítica, que México ha cambiado desde aquel entonces, por la precariedad del trabajo y la retracción de la economía: "eso no es así ahora en México, ni en muchos otros países, tampoco en Argentina, donde empiezan a notarse iniciativas legales de discriminación fuerte" (p. 109). 


\section{Hibridación multiplicada}

Por lo pronto, es importante otra cosa: nos urge resaltar algunas ideas fundamentales del esfuerzo intelectual de García Canclini, que lo abre a nuevas ideas y fronteras. Dado que en esta reseña no se pueden resumir con facilidad todos los temas que ha tocado en su copiosa obra - aunque el libro ayuda considerablemente en esta tarea-, me limitaré a tres temas clave: la hibridación, la interculturalidad y la cultura de la precariedad.

El libro Culturas híbridas... fue sin duda uno de sus aportes más importantes, por lo menos en los años noventa, en México y Latinoamérica, sin mencionar otros lugares del mundo. La presencia de este concepto en este libro de conversaciones es una prueba de que el tema ha sido actual hasta hoy: la hibridez se volvió un fenómeno mundial que cambiaba de forma en aras de las especificidades locales.

¿Cómo conceptualiza García Canclini la "hibridación”? ¿En qué consiste su aporte más interesante? Su sensibilidad y experiencia filosófica le salvan de ofrecer definiciones malabaristas del término; está lejos de esencializar los conceptos de los cuales se apropia. Cuando su interlocutora - Greeley - sugiere tres acepciones de la palabra "hibridez" - la primera refiere a una "condición inestable", la segunda al antónimo de "hegemónico" y la tercera a "una "condición de modernidad"-, él le contesta sin titubear: "la hibridación es una palabra muy amplia, que tú has considerado interpretable en tres líneas, yo creo que hay veinte modos de nombrar esos cruces, esas mezclas que en ese momento comenzaron a asombrarnos, pero que hoy son bastante obvias" (p. 85). Pero si la hibridez significa lo mismo que fusión, ¿para qué tanta insistencia en "hibridar" en lugar de "fusionar" o "mezclar"?

La otra cita de García Canclini aclara mejor de lo que se trata: de un cierto modelo de la sociedad, no de cualquier fusión. Por ejemplo, en México, los indígenas que vivían bajo las condiciones del capitalismo aprovechaban el tiempo libre entre la siembra y la cosecha para salir a las ciudades a vender sus mercancías; al regresar a las comunidades, sin embargo, no se contentaban con la manutención de sus familias sino que invertían en las fiestas y mayordomías:

Todo eso tenía que ver poco con la lógica "moderna" capitalista de acumulación [...]. Lo que se entendía como modernidad capitalista — como modo de organizar la producción, el lucro, la inversión de las ganancias obtenidas - no era la lógica de los campesinos o los artesanos que, sin embargo, estaban integrados al capitalismo (pp. 81-82).

"Hibridez" no significa tanto "fusión" simpliciter, sino más bien la coexistencia, siempre desigual, de diferentes tradiciones dentro de una sociedad; no es un compuesto sino una mezcla, refiere a la posibilidad de transcender la forma de la vida propia, la posibilidad de pasar de un lado a otro, de encontrarse y desencontrarse nuevamente; refiere más bien a la transterritorialización, no a la desterritorialización. Este uso de "hibridez" reconoce una "interdependencia globalizada y, al mismo tiempo, formas de arraigo que son importantes para todos, vivamos como migrantes o como nativos" (p. 87).

El concepto de "hibridación" fue reelaborado, reacomodado, y finalmente, reafirmado. En 2001, García Canclini escribió una introducción a la nueva edición de Culturas híbridas..., en la cual intentó retomar las críticas que se habían hecho a su libro a lo largo de una década. Lo cierto es que los argumentos que él menciona, que se habían lanzado contra sus ideas, no eran muy convincentes: se le objetaba que le hacía falta resaltar la cuestión feminista, que la presencia de la cultura afroamericana brillaba por su ausencia, que le faltaba poner énfasis en las contradicciones del capitalismo... Claro está que esta 
clase de argumentos remite a lo que le hace falta al libro y no a lo que la concepción de la hibridación realmente aportaba a los estudios sobre la cultura capitalista globalizada. ¿Acaso la obra de García Canclini no merece mejores críticas?

Quizá la objeción más obvia es ésta: si la "hibridación es una palabra muy amplia” y hay "veinte modos de nombrar esos cruces, esas mezclas" (p. 85), ninguna teoría de la hibridación es posible. Esta objeción se parece a la que Ludwig Wittgenstein (1992) había lanzado contra la teoría de los sueños de Sigmund Freud. La teoría explicativa opera con éxito siempre y cuando los fenómenos que se explican sean homogéneos y no heterogéneos. Si en lugar de una sola "hibridez" existen 20 "hibrideces", ¿cómo podemos reflexionar sobre la hibridez? Lo único que se podría mencionar en defensa de la propuesta de las culturas híbridas es su carácter de nueva manera de describir la realidad social globalizada, no una nueva manera de explicarla.

¿Por qué, entonces, la reflexión sobre la hibridez aplicada a las culturas populares y el arte, inter alia, fue una aportación original y novedosa al pensamiento latinoamericano y mundial? Vale la pena mencionar dos causas de su expansión. La "hibridación" no refleja el movimiento lineal de un proceso histórico inexorable a través de las etapas encapsuladas en los conceptos de premodernidad, modernidad, posmodernidad, pensados por los liberales esperanzados en superar las etapas menos perfectas en un crisol multicultural. La cultura popular, por ejemplo, no es, como insisten algunos marxistas, una forma de resistencia al capitalismo globalizado sino un resultado de las contradicciones inherentes en aquél, una de muchas oposiciones presentes en una coincidentia opositorum total del sistema capitalista global. Un ejemplo: la arena heteroglósica bajtiniana o la ideología heterogénea de Gramsci. Hablar de las contradicciones del sistema capitalista globalizado trajo nuevas esperanzas y con ellas nuevas maneras de enfrentar al capitalismo globalizado - este monstruo grande que pega fuerte-

\section{El reto de la interculturalidad}

Una de las esperanzas encontró expresión en el fenómeno que siempre ha acompañado a la hibridización y la globalización: la interculturalidad. No se trata de un concepto primus inter pares, se trata de un concepto que le da continuidad a la obra de García Canclini, su concepto predilecto, que aparece en el título del presente libro: "la interculturalidad y sus imaginarios". Pero, por más paradójico que sea, la interculturalidad no ocupa un lugar prevaleciente en las conversaciones, como si se asumiera que es una bisagra en la obra de García Canclini, algo dado que no necesita explicarse más. Aparece en expresiones como la ya citada: "sentido migratorio intercultural", referente a la experiencia "intercultural que consistía en transitar entre la religión bautista de sus padres, el movimiento ecuménico, y la filosofía" (p. 56). En otra conversación, dice: "hay dificultades en toda interculturalidad, y los argentinos somos en México aquellos sobre los que hay más chistes porque hay cierta incompatibilidad de caracteres, modos de ser y de hablar" (p. 109). En la sexta conversación se refiere a la misma experiencia personal como "entrenarse para el extrañamiento", como la "migración de una disciplina a otras o varias". Todas estas formas de extrañamiento son intentos de "alejarse de aquello en lo que uno se formó o aquello que se daba por supuesto" (p. 282).

Nuestra imagen del uso que García Canclini le da a la interculturalidad se complementa al leer libros anteriores a Conversaciones... Ya en Las culturas populares en el capitalismo (1982: 39), ponía en la picota el relativismo cultural, esta "concepción atomizada y cándida del poder” que sitúa a cada cultura "en su vitrina, imperturbable ante la proximidad de las demás"; la interculturalidad es la que niega el relativismo cultural de manera cotidiana, "cuando las personas deben elegir entre costumbres y valores antagónicos".

En el libro La globalización imaginada, publicado en 1999, reafirma que la interculturalidad 
reemplaza la multiculturalidad basada en la yuxtaposición de las culturas dentro de una sola nación, al situar a los sujetos en un nuevo mundo global fundamentado en las interdependencias transnacionales: las experiencias interculturales "están llen[a]s de relatos de desgarramiento y conflictos, fronteras que se mueven y anhelos de restaurar unidades nacionales, étnicas o familiares perdidas" (1999: 34). De esta manera, la interculturalidad y la globalización se deben tratar como cara y cruz de la misma moneda. García Canclini no se vuelve profeta de los "relatos épicos" de la globalización, que aseveran que los conflictos característicos de la interculturalidad se eliminarán con el tiempo; tampoco misionero de las "narrativas melodramáticas" que presentan los dolores y las violencias interculturales como resistencias al orden global listo para acabar con las diferencias de las culturas locales. Lo que le interesa es saber "qué acontece cuando ambos movimientos coexisten" (1999: 34).

En Diferentes, desiguales y desconectados. Mapas de la interculturalidad (2004), subraya más positivamente que "al relacionarnos unos con otros, aprendemos a ser interculturales" (2004: 34). Se repite la idea básica de que el multiculturalismo y el interculturalismo "implican dos modos de producción de lo social"; mientras que el primero "supone aceptación de lo heterogéneo", el segundo "remite a la confrontación y el entrelazamiento, a lo que sucede cuando los grupos entran en relaciones e intercambios [...], implica que los diferentes son lo que son en relaciones de negociación, conflicto y préstamos recíprocos" (2004: 14-15).

Las dudas que acechan al lector de estas líneas no son de la misma especie. García Canclini supone que entre las personas que representan valores antagónicos puede entablarse una negociación cuya culminación será la elección entre estos valores antagónicos. Pero, "negociar" entre A y B no significa que el sujeto comprende mejor $\mathrm{A}$ y $\mathrm{B}$, sino algo tan sencillo como estar en contacto con A y
B. La gramática de elegir nos muestra que la postura interculturalista es endeble. Si uno elige, siempre elige entre algo y algo. Pero si B es una alternativa para A, A y B son dos sistemas de valores antagónicos, y en este sentido, estables y no mezclados. Pero hay más plagas en el costal. ¿Quién es el enigmático sujeto que elige entre valores antagónicos? Para que alguien sea capaz de elegir, debe estar familiarizado con la práctica de elegir, tener una identidad. La negociación entre las identidades supone ya una identidad previa. Los que eligen, los que negocian, los interculturales, deben haberse formado en un espacio no intercultural, o sea, capitalista. El modelo de un elector fantasma que se mueve entre diferentes valores antagónicos como el consumidor entre diferentes platillos de un buffet, no proviene de un espacio intergaláctico sino de un espacio concreto de la cultura occidental, liberal, consumidora.

\section{Las mazmorras de la precariedad}

No cabe duda de que el capitalismo global ha pasado, por lo menos a partir de 2008, por una crisis no sólo económica sino también política y social. Otro relato grande, para usar la fraseología de JeanFrançois Lyotard (1987), se ha vuelto escombros; pero antes de morir, ha hecho su parte desestabilizando otras formas de vida más tradicionales, basadas en lazos comunitarios y economías locales. Una de las características del "capitalismo en desintegración” es lo que García Canclini llama la precariedad, es decir:

La inestabilidad y la sensación de vivir en emergencia, no solo de la emergencia de lo nuevo sino emergencia de riesgo. Ya no la experimentan los creadores, sino que hay una precariedad generalizada de las nuevas generaciones en cuanto a la condición económica, laboral, social y cultural en la que estamos ahora internacionalmente (p. 288). 
Precisamente, los jóvenes son los que "aparecen como un lugar estratégico para la comprensión de la crisis del capitalismo y de la modernidad" (p. 302). Lo que García Canclini dice al respecto aclara mejor los concomitantes de este fenómeno. Todavía en La sociedad sin relato. Antropología y estética de la inminencia (2010: 196), siguiendo a Marc Abélès, atribuía el aumento de la precariedad y la incertidumbre a la atrofia del Estado y su función de controlar los riesgos sociales. La desconfianza en el Estado y otras grandes instituciones explica por qué en este mundo ganan confianza las organizaciones no gubernamentales como Greenpeace o Amnistía Internacional, y los performances de los artistas. Las primeras y los segundos muestran una visibilidad en lugares concretos, se dedican a la lucha por la supervivencia económica o ecológica. Unos y otros trabajan con fragmentos del mundo, le dan cierta visibilidad a lo inminente y muestran cómo puede actuarse aun desde visiones incompletas.

Otro gran fenómeno que, por una parte, acompaña la precariedad, y por la otra, la aumenta, es el terror que causan las grandes migraciones. En primer lugar, crece la inseguridad económica: "han desbordado la capacidad de incorporarlos al mercado de trabajo como una fuerza a la que se le puede pagar más barato el salario y no darle seguridad" (p. 302). Por otro lado, los países de Europa, y ahora también de Latinoamérica, "no saben qué hacer, además, con los conflictos interculturales, porque llega gente con otras prácticas, otras religiones" (p. 302). En respuesta, el capitalismo global, con su lógica de lucro, hace la pregunta: ¿cuánta gente cabe? Los Estados, por su parte, "ensayan” otras soluciones; por ejemplo, delegar responsabilidades: "más o menos desde los años ochenta, la consigna es que hay que adelgazar el Estado, hay que gastar menos en salud, menos en seguridad, menos en jubilaciones. Entonces el Estado se desresponsabiliza y dice: 'cada uno tiene que arreglárselas"” (p. 303). El discurso posmoderno tampoco se mostró inocente, como observó García Canclini en 2010. El elogio posmoderno de lo efímero y flexible ha ocultado la precariedad social; el posmodernismo se jactaba de abatir los grandes relatos, pero descuidaba la concentración de grandes poderes (2010: 251).

Para explicar el fenómeno de la precariedad, ofrece un argumento que da al capitalismo: "la precariedad surge de tener pocos amarres, pocas ubicaciones claras en la sociedad" (p. 288). En efecto, conduce a las estrategias de prevención y precaución. Claro está que se podrían agregar otras cosas: la dependencia de los descubrimientos tecnológicos o las dependencias del mercado global. Pero, para García Canclini, no sólo hay muchas causas de la precariedad sino muchas formas:

La precariedad de un hijo de una familia que le puede pagar los estudios en una universidad privada - como ocurre con miles en la Ciudad de México, que son hijos de profesionales — no es la misma precariedad de migrantes que viven desplazamientos por tercera o cuarta generación, desubicaciones de la sociedad sin expectativas de estar mejor en el futuro [...], donde las utopías se han quedado como rezagos o sólo reaparecen bajo formas religiosas o pararreligiosas (p. 288).

En este punto, estamos tentados a decir: la atmósfera de precariedad en la situación de desigualdad implica la desigual vulnerabilidad; a saber, los que están en una situación más desfavorable muestran mayor vulnerabilidad. Mientras que la precariedad refiere a la "inestabilidad" y la vida "en emergencia", la vulnerabilidad se identifica con la indefensión frente a estos riesgos. Alguien puede vivir en la precariedad, pero no mostrar vulnerabilidad. Además, la tesis de que hay muchas formas de precariedad se somete a la misma crítica que la idea de que hay 
muchas formas de hibridez. A pesar de las dudas y críticas que despiertan las ideas de García Canclini, una cosa es cierta: al leer La interculturalidad y sus imaginarios: conversaciones con Néstor García Canclini, nos volvemos menos inocuos y más críticos de la brutal realidad que se impone en nuestras vidas. D

\section{Bibliografía}

García Canclini, Néstor, 1982, Las culturas populares en el capitalismo, Nueva Imagen, México.

—_ 1999, La globalización imaginada, Paidós, Buenos Aires.

2001 [1989], Culturas hibridas: estrategias para entrar y salir de la modernidad, Paidós, México.

, 2004, Diferentes, desiguales y desconectados. Mapas de la interculturalidad, Gedisa, Barcelona.

- 2010, La sociedad sin relato. Antropología y estética de la inminencia, Katz, Buenos Aires.

Lyotard, Jean-François, 1987, La condición postmoderna. Informe sobre el saber, Cátedra, Madrid.

Wittgenstein, Ludwig, 1992, Lecciones y conversaciones sobre estética, psicología y creencia religiosa, Paidós, Barcelona. 